\title{
Prognostic Factor
}

National Cancer Institute

\section{Source}

National Cancer Institute. Prognostic Factor. NCI Thesaurus. Code C18959.

The general personal and health characteristics that have a bearing on the course of a disease and its eventual outcome. 